\title{
PLANNING SUSTAINABILITY IN HIGHER EDUCATION: THREE CASE STUDIES
}

\author{
MARCO SCHIAVON ${ }^{1}$, MARCO RAGAZZI $^{1}$, ELENA MAGARIL $^{2}$, MAXIM CHASHCHIN $^{2}$, \\ ANZHELIKA KARAEVA ${ }^{3}$, VINCENZO TORRETTA ${ }^{3}$ \& ELENA CRISTINA RADA ${ }^{3}$ \\ ${ }^{1}$ Department of Civil, Environmental and Mechanical Engineering, University of Trento, Italy \\ ${ }^{2}$ Department of Environmental Economics, Ural Federal University, Russian Federation \\ ${ }^{3}$ Department of Pure and Applied Sciences, Insubria University, Italy
}

\begin{abstract}
Sustainable development is a key principle of national and international policies, which has been strongly promoted by the European Union since 2015. Communication, education, the awareness of the importance of accelerating the transition from a linear economy to a circular one and of raising environmental awareness play a key role in the achievement of sustainable development goals (SDGs). To achieve the goals on a large scale, it is necessary to start from a local scale. In this sense, universities must experiment best practices and make them available to the society. In the last years, many universities have adopted environmental sustainability plans in order to implement green policies and develop a roadmap towards the achievement of the SDGs, while sharing best practices with university communities and society. This paper presents the case of two Italian universities and a Russian one. Specifically, the paper presents the contents of the current environmental sustainability plans of the Italian universities, discussing the reasons for the choice of the environmental sustainability goals and the expected results following the implementation of the related actions. A comparison between the approaches adopted in the sustainability plans of the two Italian universities will be presented in details. In addition, the paper analyses the potential implementation of a sustainability plan in the Russian university. The paper will discuss also potential criticalities in the achievement of the goals.

Keywords: environmental sustainability, sustainable development, planning, university networks, waste management, emissions, energy efficiency, mobility, health, communication.
\end{abstract}

\section{INTRODUCTION}

According to the Brundtland report, sustainable development can be defined as a modification process that aims at the harmonization of the exploitation of resources, of investments, of the direction of the technological development and of institutional reforms and advances with the needs of future generations, in addition to the current one [1]. After the commitments undertaken by the states that endorsed the Kyoto Protocol, which aims at reducing the greenhouse gas (GHG) emissions, increasing the energy efficiency and the production of energy from renewable sources, the interest of the public opinion towards environmental sustainability has considerably grown. In this framework, academic institutions play a fundamental role, acting as catalysts for innovation and disseminators of knowledge and good practices of environmental sustainability through their high-level educational programs [2], student engagement [3] and communication campaigns [4]. During the last decades, a growing number of universities have signed Sustainability in Higher Education declarations, to confirm their commitments towards environmental sustainability actions in education and research [5]. This phenomenon has gone hand in hand with the development of rankings for higher education institutions, with the purpose of measuring their environmental sustainability performance and stimulating the achievement of higher targets [6].

During the last decade, the number of universities pursuing targets of environmental sustainability has considerably increased, as demonstrated by more than 800 peer-reviewed publications on this topic. The increasing awareness of the role of universities in promoting 
environmental sustainability principles has led to the formation of university networks for the exchange of good practices, like the case of the Network of Universities for Sustainable Development (RUS), which was formed in Italy in 2015 [7]. RUS currently includes 78 universities of every size and location. The purpose of this network is to share solutions to increase the level of environmental sustainability and social responsibility among universities. RUS makes a clear reference to the 17 Sustainable Development Goals (SDGs), considered as the key targets to design the path towards higher sustainability levels in academic education. Several universities belonging to RUS have developed Environmental Sustainability Plans (ESPs) to plan and monitor activities that aim at increasing the level of sustainability within the academic communities and outside. Meanwhile, since the last decade, universities have had the opportunity to measure their progress and stimulate further achievements with the participation in university sustainability rankings. Among them, the UI Green Metric (UI GM) World University Rankings [8] and the Times Higher Education (THE) Impact Rankings [9] have involved a high number of universities sharing their levels of sustainability in recent years.

The present paper aims at presenting the cases of two Italian universities (the University of Trento and the Insubria University) and their respective ESPs. Differences and similarities will be highlighted between the two universities. In addition, the present paper will investigate the potential implementation of an ESP in a Russian university (the Ural Federal University) that has demonstrated growing sensitivity to the topic of environmental sustainability in the last decade. The paper will contribute to enriching the series of publications on sustainability in higher education with a focus on two different countries with similar motivations in the promotion of good practices of sustainability in university environments.

\section{CASE STUDIES}

\subsection{University of Trento}

The first case study refers to the University of Trento (UniTrento), located in the Trentino region (Italy). Trentino is an Alpine region with a high touristic vocation, a long tradition of respect for the environment and a strong bond with landscape and nature [10]-[12]. In 2018, UniTrento was composed of 16,305 students, 889 doctoral students and post-doc fellows, 673 professors and researchers, and 693 staff employees. UniTrento consists of ten departments, one faculty and three inter-departmental centres, displaced in five geographic areas: downtown Trento, Eastern hills of Trento, the town of Rovereto, the hamlet of Mattarello and the village of San Michele all'Adige (Fig. 1).

Considered that the populations of Trento and Rovereto (the main municipalities that host the Unitrento campuses and research centres) account for 118,288 and 39,972 inhabitants, respectively [13], the university community represents $11.7 \%$ of the whole population living in those two towns. Such numbers cause a high degree of environmental pressure to the municipalities involved, in terms of mobility, consumption of natural resources and waste generation [14], [15].

In 2016, for the first time, UniTrento issued a document entirely dedicated to environmental sustainability, with a road map for the achievement of 14 different targets grouped in four areas: "Emissions, energy and natural resources", "Buildings and procedures", "Culture and education" and "Health and well-being" [16]. Being this a first attempt to reach several ambitious targets in a unified manner, the pathway revealed as 


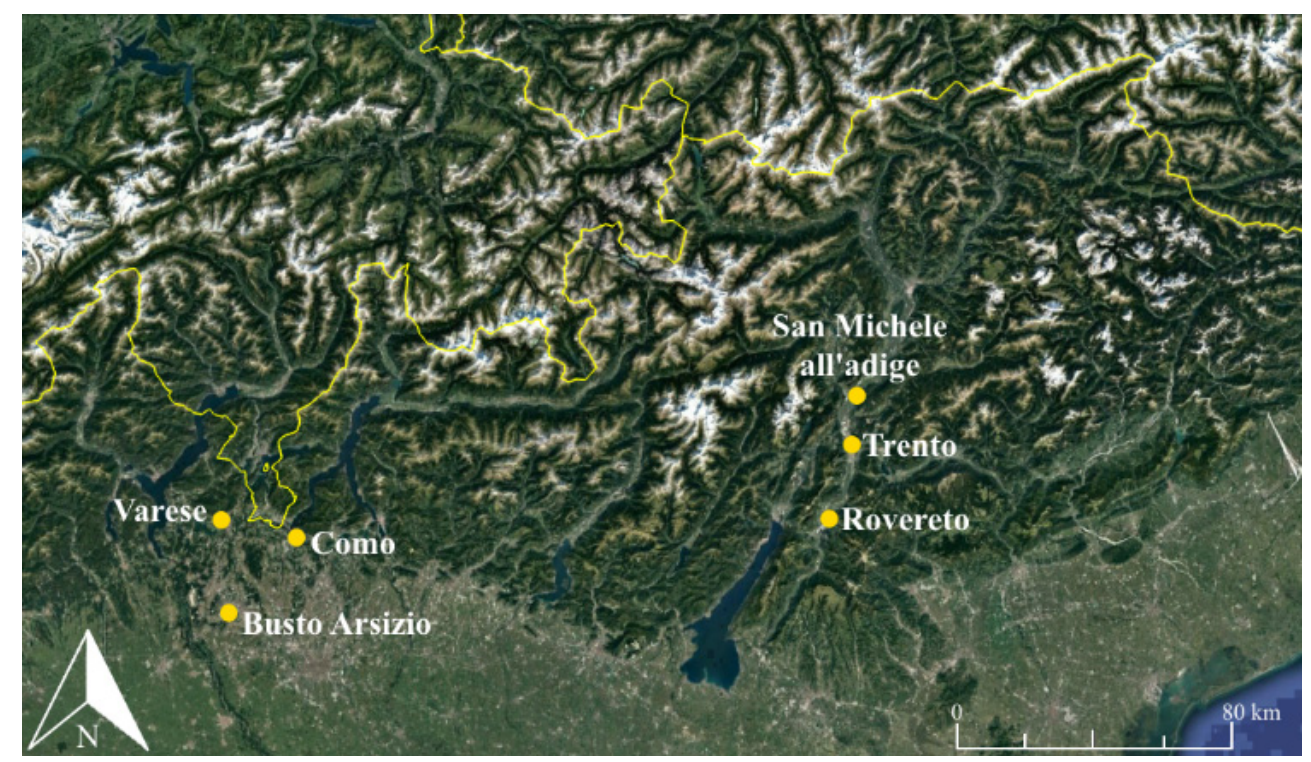

Figure 1: Location of the UniTrento and Uninsubria campuses in northern Italy. (Source: Adapted from Google [17].)

arduous, partly because of the high number of targets. However, that 2-year period allowed highlighting issues whose entity was new at that time: problems regarding waste management, issues concerning the second area ("Buildings and procedures"), difficult collection, circulation and management of data within the different universities departments. In 2019, a new ESP (version 2020/2021) was drafted to increase the level of sustainability of the university and continue the path started in 2016.

\subsection{Insubria University}

The Insubria University (Uninsubria) is composed of about 12,000 students and hosts about 15,400 people in total, including lecturers, researchers, administrative and technical staff. Uninsubria was founded in 1998 and consists in three main campuses located in the towns of Varese, Como and Busto Arsizio (Fig. 1). The three campuses are composed of about 40 buildings in total. Uninsubria hosts seven departments. Three of them are located in Como and the remaining four departments are located in Varese. One of the departments of Varese has also a branch in Busto Arsizio.

Uninsubria formally started its path towards sustainability initiatives in 2016, when the university joined the RUS and drafted its Strategic Plan for Sustainable Development. The latter was concretely realized with the approval of the Environmental Sustainability Plan 2019/2020, containing proposals for initiatives and a roadmap to implement actions for reducing the environmental pressure of the campuses, improving the quality of life of the users and promoting the culture of sustainability. Concerning this last aspect, Uninsubria believes that becoming an example of virtuous community would be beneficial to other sectors of the public administration, of education and to the territory in general. 


\subsection{Ural Federal University}

The Ural Federal University (UrFU), named after the first President of Russia B.N. Yeltsin (UrFU), is located in Ekaterinburg (Russia). UrFU is composed of about 56,000 students and is divided into 14 buildings. This makes UrFU the largest Russian federal university. Moreover, UrFU has six subsidiaries in Sverdlovsk region as reported in Fig. 2 [18], [19].

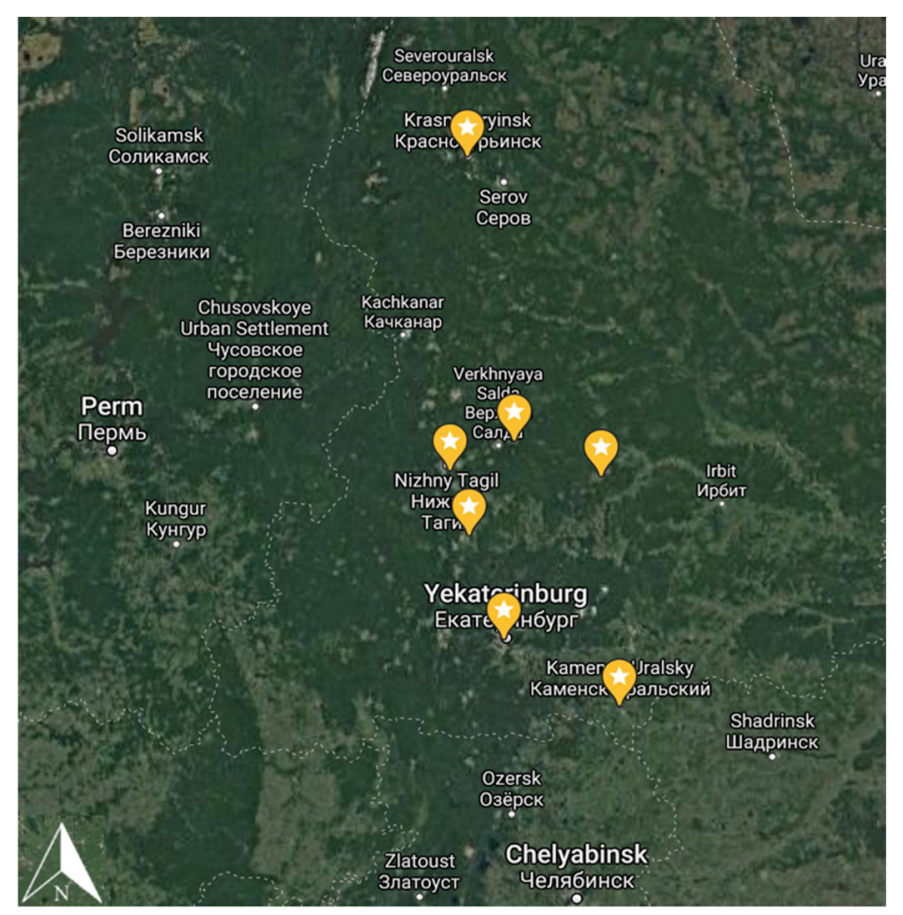

Figure 2: Location of the UrFU campuses. (Source: Adapted from Google [17].)

UrFU has a Development Program for 2010-2020 that includes five main sectors [20]: Educational activities; Research activities; Human Resource Development; University infrastructure development and Organizational development.

Global development trends were considered, as well as the situation in the Russian economy and the Ural Federal district. Since 2019, Ural Federal University has been implementing a digital transformation program that develops existing information services and creates new ones.

\section{ENVIRONMENTAL SUSTAINABILITY PLANNING}

\subsection{University of Trento}

The Environmental Sustainability Plan 2020/2021 aims at pursuing higher sustainability levels through two modalities: a participation process and a proposal for technical actions resulting from the previous two-year period. The participation process will allow the community making proposals, discussing ideas and strategies complementing the technical 
actions. One of the tools available to the community will be the UniTrento Environmental Sustainability Days, which will take place annually. During such events, the community will be able to discuss ideas, highlight criticalities and propose strategies, together with experts of the university in environmental sustainability.

Concerning the technical part of the Plan, the sustainability targets are organised in four sectors, including 11 subsectors (Table 1). Each sector includes the United Nations Sustainable Development Goals (SDGs) targeted [21].

Table 1: Organization of the technical targets of the ESP 2020/2021 of UniTrento.

\begin{tabular}{|l|l|l|l|l|}
\hline \multirow{5}{*}{} & \multicolumn{4}{|c|}{ Sectors } \\
\cline { 2 - 5 } & $\begin{array}{l}\text { Emissions, energy and } \\
\text { natural resources }\end{array}$ & $\begin{array}{l}\text { Buildings and } \\
\text { procedures }\end{array}$ & $\begin{array}{l}\text { Communication } \\
\text { and culture of } \\
\text { sustainability }\end{array}$ & $\begin{array}{l}\text { Health and } \\
\text { well-being }\end{array}$ \\
\hline \multirow{5}{*}{ Subsectors } & $\begin{array}{l}\text { University carbon } \\
\text { footprint } \\
\text { Renewable energy } \\
\text { Waste management } \\
\text { Drinkable water } \\
\text { management }\end{array}$ & $\begin{array}{l}\text { Consumption } \\
\text { monitoring } \\
\text { system } \\
\text { Green } \\
\text { procurement }\end{array}$ & $\begin{array}{l}\text { Sustainability } \\
\text { communication } \\
\text { Curriculum of } \\
\text { studies }\end{array}$ & $\begin{array}{l}\text { Indoor air } \\
\text { quality } \\
\text { Working life }\end{array}$ \\
\hline $\begin{array}{l}\text { SDGs } \\
\text { targeted }\end{array}$ & $\begin{array}{l}\text { n. 7: Affordable and } \\
\text { clean energy } \\
\text { n. 11: Sustainable } \\
\text { cities and communities } \\
\text { n. 12: Responsible } \\
\text { consumption and } \\
\text { production } \\
\text { n. 13: Climate action }\end{array}$ & $\begin{array}{l}\text { nesponsible } \\
\text { consumption } \\
\text { and } \\
\text { production } \\
\text { n. 13: Climate } \\
\text { action }\end{array}$ & & \\
\hline
\end{tabular}

Regarding sector n. 1 ("Emissions, energy and natural resources"), the Plan has declared a set of targets to achieve an efficient use of resources and minimize waste production. Specifically, regarding subsector n. 1.1 ("University carbon footprint"), the Plan aims at providing a yearly estimate of the GHG emissions from electric energy use, thermal energy use and mobility of staff, professors, researchers and students. The inclusion of subsector $n$. 1.2 ("Renewable energy") in the Plan is motivated by the following reason: in the Italian public sector, every year the companies that supply electric energy are selected through a tender noticed by the Ministry of Economy and Finance. Since the evaluation is not based on environmental criteria, but only on the lowest price, the suppliers are often unable of granting a large share of renewable sources in the energy mix. UniTrento currently compensates for this drawback by producing electric energy from photovoltaic panels installed on the roof of the Central University Library. However, the Plan indicates that renewable energy production should be increased by equipping future university buildings with systems for the production of electric and/or thermal energy by renewable sources. Waste management (subsector $\mathrm{n}$. 1.3 ) is a particularly critical sector. External contributions of waste by strangers have been noticed in the past years in the areas outside the university buildings that host the dumpsters, which are periodically emptied by the municipal utility in charge. Since the taxes for waste management are calculated on the basis of the number of times each dumpster is emptied by the local utility, external contributions imply additional costs. Furthermore, if dumpsters are 
not properly locked after the disposal of waste by the personnel, the local utility may proceed to empty dumpsters that might be only partially filled. This translates into additional (and avoidable) costs for a public university. UniTrento intends to propose guidelines for the surveillance of the external areas, installing water dispensers in proximity of the vending machines to discourage the purchase of water in PET bottles, replacing paper towels with electrical hand-dryers [12], supporting specific projects proposed by the community, banning single-use plastics from bars, canteens and catering services. Subsector n. 1.4 ("Drinkable water management") prescribes a census of the status of public toilets in UniTrento, as a preparatory step towards the introduction of water-saving devices on the restrooms' taps. The last subsector (n. 1.5, "Sustainable mobility") aims at improving the conditions of public and shared transport and favor forms of mobility with lower environmental impacts. The criticalities of the town of Trento in terms of mobility were described in a recent publication [15].

Sector n. 2 ("Buildings and procedures") includes two subsectors. Subsector 2.1 ("Consumption monitoring system") aims at gradually automating the monitoring of water and electric/thermal energy in the buildings of UniTrento. Subsector 2.2 ("Green procurement") aims at implementing a homogeneous green procurement policy at every level in UniTrento.

Sector n. 3 ("Communication and culture of sustainability") plays a fundamental role in raising the community's awareness of the present challenges and of the opportunities deriving from increasing the level of environmental sustainability of UniTrento. Subsector 3.1 ("Sustainability communication") is designed to specifically meet these targets and to increase the visibility of UniTrento (both internally and externally) on sustainable development. In addition, this subsector includes the organization of the Environmental Sustainability Days and the production of scientific contributions on sustainability. Given the key role of students, UniTrento aims at improving its teaching programs on sustainability. Subsector 3.2 ("Curriculum of studies") is designed to achieve these targets.

Sector n. 4 ("Health and well-being") includes a set of actions aimed at improving the quality of life of the university community. The first subsector (4.1 "Indoor air quality") was created as a response to the relatively high concentrations of carbon dioxide $\left(\mathrm{CO}_{2}\right)$ in indoor air. Although in classrooms/offices $\mathrm{CO}_{2}$ concentrations are not critical for human health, symptoms similar to the so-called "sick-building syndrome" may occur [22], [23]. To reduce the $\mathrm{CO}_{2}$ concentrations within acceptable levels, the Plan aims at mapping structural and installation issues that may negatively affect indoor air quality, monitoring indoor air quality to highlight possible criticalities, and developing guidelines to manage indoor air. Meanwhile, initiatives concerning the work/home balance are also considered (subsector 4.2 "Working life"). In addition to the ongoing initiatives supporting parenthood, the Plan intends to achieve additional targets: 1) create spaces dedicated to the personal well-being and the health of people, where people can spend some time for health reasons; 2) create "silence spaces", dedicated to whom needs quite moments for meditation or praying during the working day; 3) renovate sport facilities; 4) improve the indoor visual comfort; 5) improve the communication to the community concerning the routes to reach classrooms, offices and other key destinations of the university, with specific regards to handicapped people.

\subsection{Insubria University}

In 2019, Uninsubria generated the second version of its Environmental Sustainability Plan, whose duration, similarly to UniTrento, is 2 years. The Environmental Sustainability Plan 
considers four sectors and nine targets (Table 2). Regarding the first sector (Emissions, energy and natural resources), the Uninsubria aims at estimating the carbon footprint of the university on the basis of the methodology recently developed by RUS [24]. The workgroup on climate change will strongly cooperate with the mobility workgroup in case mobility reveals as the primary sector contributing to carbon emissions. Specifically, Uninsubria will evaluate strategies to raise the awareness of the users to the use of public transport and car sharing/pooling services, and will implement actions to improve the offer of public transport in the area. GHG emissions are also strongly related to the consumption of fossil fuels for heating. Thus, Uninsubria aims at reducing the energy consumption in buildings, but also evaluating initiatives to become producer of electric energy from renewable sources. Uninsubria intends to reduce the consumption of drinkable water too. However, the first essential step is a census of the sanitary appliances of the university, which may be the primary cause of excessive water consumption. In analogy with UniTrento, Uninsubria is facing the problem of residual waste [18], caused primarily by the presence of a few undefined waste bins located in the university buildings and by the uncontrolled external areas that host waste dumpsters. The Plan proposes actions for the removal of undefined waste bins, protocols for the surveillance of external areas and initiatives to raise the users' awareness on responsible consumption and proper waste disposal through dedicated communication campaigns.

Table 2: Organization of the technical targets of the ESP 2019/2020 of Uninsubria.

\begin{tabular}{|l|l|l|l|l|}
\hline \multirow{2}{*}{} & \multicolumn{3}{|c|}{ Sectors } \\
\cline { 2 - 5 } & $\begin{array}{l}\text { Emissions, energy } \\
\text { and natural } \\
\text { resources }\end{array}$ & Mobility & $\begin{array}{l}\text { Culture and } \\
\text { education }\end{array}$ & Health \\
\hline \multirow{5}{*}{ Subsectors } & $\begin{array}{l}\text { CO } \text { emission } \\
\text { inventory University } \\
\text { and carbon footprint } \\
\text { Energy efficiency, } \\
\text { renewable energy } \\
\text { and buildings } \\
\begin{array}{l}\text { Reduction of } \\
\text { drinkable water } \\
\text { consumption } \\
\text { Waste management }\end{array}\end{array}$ & $\begin{array}{l}\text { Sustainable } \\
\text { mobility }\end{array}$ & $\begin{array}{l}\text { Sustainability } \\
\text { Sustainability } \\
\text { office } \\
\text { Curriculum of } \\
\text { studies }\end{array}$ & $\begin{array}{l}\text { Health and } \\
\text { well-being } \\
\text { in } \\
\text { workplaces }\end{array}$ \\
\hline
\end{tabular}

Sector n. 2 ("Mobility") deals with the proposal for initiatives in the field of sustainable mobility. Uninsubria has already obtained important results in this sector. More specifically, the university signed an agreement with a well-known private company offering bus transportation services, which allows students and personnel to purchase travel tickets at a discount price. An agreement with the local public transportation company allowed improving the frequency of the existing bus routes to and from the university campuses, especially during rush hours. New routes were also added to the existing ones and a working group on the railway transport was created with the aim of improving the connection with university campuses. A questionnaire on the needs in terms of mobility was distributed to the users of the campus of Como and a worktable on the local mobility was set up in cooperation with the local administration. 
Regarding sector n. 3 ("Culture and education"), Uninsubria aims at organizing an event every year involving RUS members and taking part in events on sustainability, both at a national and international level. Uninsubria considers the option of participating in international university rankings on sustainability, but only if the criteria are scientifically validated. This theme was the object of a debate in a paper concerning the UI GM university ranking, which highlighted potential limits in the formulation of the evaluation criteria [25]. Another target of sector $\mathrm{n} .3$ is the creation of an office entirely dedicated to environmental sustainability, to the management and monitoring of the initiatives listed in the Plan and to the development of new ones. Finally, Uninsubria aims at promoting the culture of sustainability by increasing the number of courses on this topic and promoting both internships in companies working on themes related to environmental sustainability and theses on this topic.

Sector n. 4 ("Health") primarily aims at protecting the health of all users (students, lecturers, researchers, administrative and technical staff) from the exposure to air pollutants that originate from cigarette smoking. Uninsubria has carried out research on this field by monitoring campaigns on the concentration of particulate matter at the entrance of buildings [26]. In addition, analogously to UniTrento, Uninsubria has planned monitoring campaigns on the concentration of $\mathrm{CO}_{2}$ in the indoor air of university buildings. Another common target with UniTrento is the proposal and implementation of initiatives to improve the quality of life at work.

\subsection{Potential implementation of an ESP at the Ural Federal University}

The theme of sustainable development is becoming a topical subject in the Russian higher education system. One of the first initiatives in the field of sustainable development of universities was the "Campus" program developed by Tetra Pak in 2013 with the support of the World Wildlife Fund (WWF). The purpose of the "Campus" program was to spread ecological awareness among students and young people [27]. The program also consisted in several eco-projects and initiatives for universities. A few years later, the program "Green universities of Russia" has evolved and got the government support. The main goal of the program is greening of Russian universities by introducing a separate waste collection system, energy saving technologies, and conducting educational activities in the field of ecology and environmental protection for students and University employees [18], [28]. $\mathrm{UrFU}$ is currently the participant of this program.

Moreover, a few Russian universities are included annually in the GreenMetric World University Rankings [8], [28]. This rating evaluates the commitment of world universities to the ideas of sustainable development and the designing of eco-friendly university infrastructure.

In order to determine the effectiveness of $\mathrm{UrFU}$ in the field of sustainable development and its perspectives, a comparative analysis of Russian universities (Ural Federal University, Moscow Institute of physics and technology, Higher school of Economics, peoples 'friendship University of Russia) in the framework of implementing sustainable development activities in 3 main areas was developed (Table 3).

According to the results, Russian universities demonstrate the high interest in the topic of sustainable development. Most of the reviewed universities are currently introducing separate waste collection system, developing programs for improving working conditions, landscaping or working on sustainable development plan, etc. 


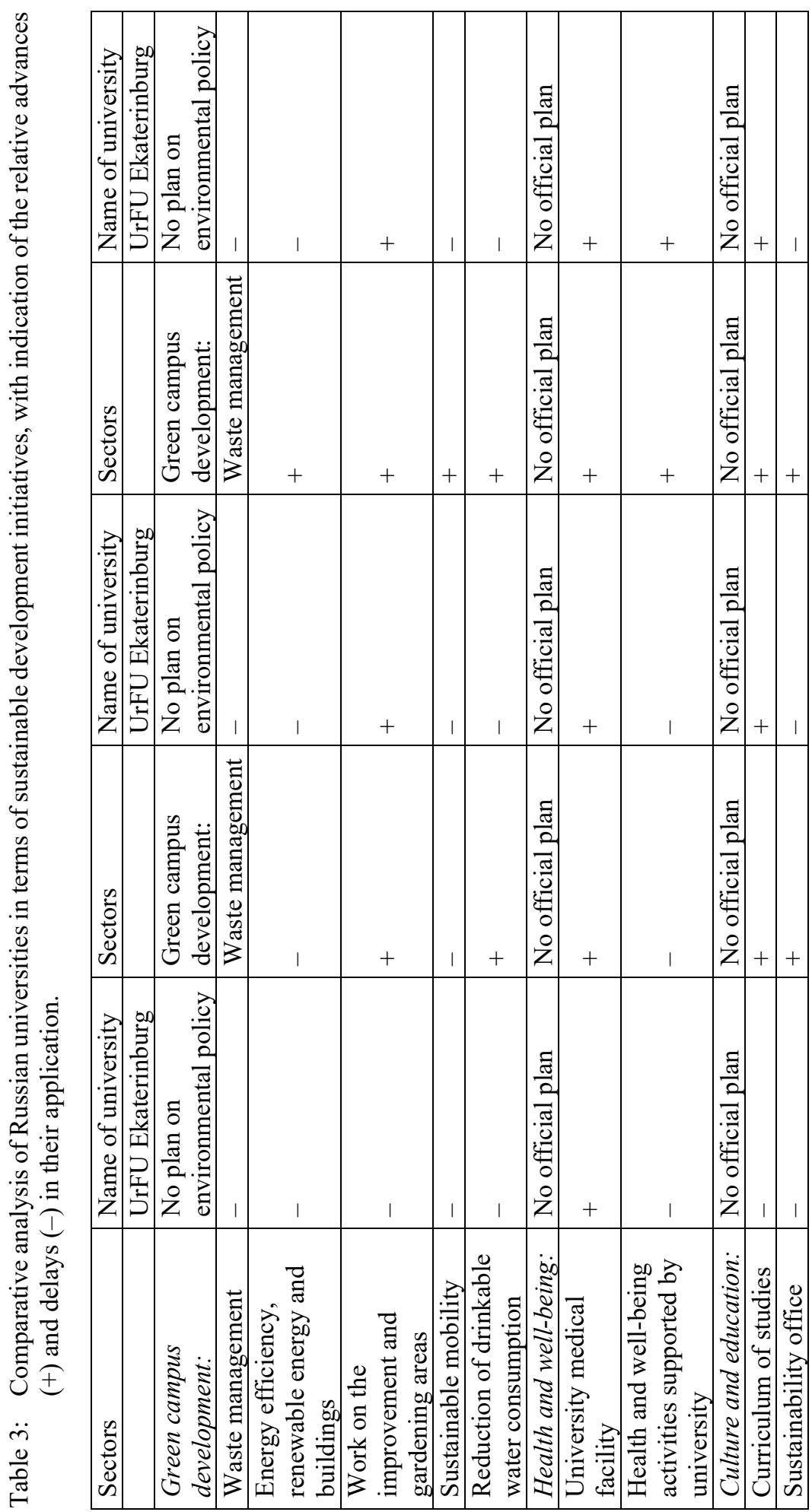

WIT Transactions on Ecology and the Environment, Vol 253, (C) 2021 WIT Press www.witpress.com, ISSN 1743-3541 (on-line) 
$\mathrm{UrFU}$ is at a very early stage of sustainable development planning: the university has implemented the separate waste collection system in several areas, participates in associations of sustainable development and develops various environmental initiatives; a special role is given also to the improving of the University infrastructure.

Digital technologies (for instance, the online portal of sustainable development) might become the basis for developing a transparent system of sustainable development at UrFU. The suggested sectors of the on-line portal are reported in Table 4. The goals are listed below:

- to ensure transparency and accessibility of data on the University's sustainable development;

- to digitize processes for evaluating the achievement of sustainable development plans;

- to create a competitive spirit between structural divisions in the field of energy saving quality;

- to develop a culture of responsible attitude towards nature in an intercultural educational environment.

Table 4: Suggested sectors of online portal about University Sustainable Development.

\begin{tabular}{|l|l|}
\hline Sector of online portal & Proposed contents \\
\hline $\begin{array}{l}\text { Separate waste } \\
\text { collection }\end{array}$ & $\begin{array}{l}\text { Map of separate waste collection systems (academic buildings } \\
\text { and dormitories); } \\
\text { Statistical data on waste collection and waste treatment; } \\
\text { Short segregation instruction for students and employees. }\end{array}$ \\
\hline Health and well-being & $\begin{array}{l}\text { Indoor air quality information; } \\
\text { Guide to healthy eating; } \\
\text { Sport activities at UrFU. }\end{array}$ \\
\hline Clean air & $\begin{array}{l}\text { Statistical data on air pollution in Ekaterinburg; } \\
\text { Statistical data on the carbon footprint produced; } \\
\text { Guide "How to reduce air pollution?" }\end{array}$ \\
\hline Energy conservation & $\begin{array}{l}\text { The information on the applicable energy saving technologies; } \\
\text { Statistical data on energy consumption in university building } \\
\text { and dormitories }\end{array}$ \\
\hline Greening of campus & $\begin{array}{l}\text { Map of campus greening; } \\
\text { Information about landscaping projects }\end{array}$ \\
\hline
\end{tabular}

UrFU has all the prerequisites for ESP developing and implementation:

- MSW selective collection system was introduced in five places at the main university building and is extending to all the UrFU.

- Heat and electricity come to the university building from the boiler-turbine of the experimental production complex of UrFU. Its eco-modernization will reduce emissions of harmful substances into the atmosphere and ensure rational resource consumption through the introduction of energy-saving technologies;

- Working together on joint "green" projects with regional enterprises, a positive impact on the indicators of environmental activity will be achieved.

\section{CONCLUSIONS}

The present paper showed how universities are preparing for the mission of pursuing higher level of environmental sustainability and promoting good practices both within universities 
and to society. Every university usually works in autonomy, but the involvement in university networks is strongly important to share principles and results.

The cases of UniTrento and Uninsubria showed that both universities have a similar scheme of actions, very likely influenced by the involvement in RUS. Both universities have to face issues, especially regarding waste management and mobility, but specific initiatives are planned in their respective ESPs.

The topic of sustainable development in the system of higher education is quite new for Russian universities, therefore it is significant for the government to provide financial support for the universities and determine the need of ESP. It is important also to develop a unified system for assessing sustainability adapted to the national legal framework in Russia.

The three universities might also commit to participate in the UI GM and THE rankings, as many of the goals presented in this paper reflect the evaluation criteria of these rankings (e.g., energy and climate change, waste, water, transportation and education in the UI GM and the contributions to the achievement of the 17 SDGs in the THE rankings). However, especially with regards to the first ranking, the selection and evaluation of the assessment criteria should overcome the limitations that affect the scientificity and rigour of the methodology [26].

\section{ACKNOWLEDGEMENTS}

This research was supported by Act 211 Government of the Russian Federation, contract № 02.A03.21.0006.

[1] United Nations, Report of the World Commission on Environment and Development: Our Common Future. www.un-documents.net/our-common-future.pdf. Accessed on: 20 Oct. 2020.

[2] Lippuner, C., Pearce, B.J. \& Bratrich, C., The ETH sustainability summer school programme: an incubator to support change agents for sustainability. Current Opinion in Environmental Sustainability, 16, pp. 37-43, 2015.

[3] Hamón, L.A.S., Martinho, A.P., Ramos, M.R. \& Aldaz, C.E.B., Do Spanish students become more sustainable after the implementation of sustainable practices by universities? Sustainability, 12, p. 7502, 2020.

[4] Gori, E., Romolini, A., Fissi, S. \& Contri, M., Toward the dissemination of sustainability issues through social media in the higher education sector: Evidence from an Italian case. Sustainability, 12, p. 4658, 2020.

[5] Grindsted, T.S., Sustainable universities: From declarations on sustainability in higher education to national law. Environmental Economics, 2, pp. 29-36, 2011.

[6] Yudkevich, M., Altbach, P.G. \& Rumbley, L.E., Global university rankings: The "Olympic Games" of higher education? Prospects, 45, pp. 411-419, 2015.

[7] Network of Universities for Sustainable Development (RUS). sites.google.com/unive.it/rus/home. Accessed on: 20 Oct. 2020.

[8] UI greenmetric world university rankings. greenmetric.ui.ac.id/. Accessed on: 21 Jan. 2021.

[9] Times Higher Education, Impact Rankings 2020. www.timeshighereducation.com/ impactrankings\#!/page/0/length/25/sort_by/rank/sort_order/asc/cols/undefined. Accessed on: 21 Jan. 2021.

[10] Rada, E.C., Bresciani, C., Girelli, E., Ragazzi, M., Schiavon, M. \& Torretta, V., Analysis and measures to improve waste management in schools. Sustainability, 8 , p. 840, 2016. 
[11] Cioca, L.I. et al., Agro-tourism and ranking. AIP Conference Proceedings, 1968, $020022,2018$.

[12] Giurea, R. et al., Good practices and actions for sustainable municipal solid waste management in the tourist sector. Resources, 3, p. 51, 2018.

[13] Italian Institute of Statistics (ISTAT). Resident population on 1st Jan.: Provincia Autonoma Trento. http://dati.istat.it/. Accessed on: 20 Oct. 2020.

[14] Schiavon, M., Ragazzi, M., Coller, G., Ferronato, N., Torretta, V. \& Rada, E.C., A methodology to support decisions towards economic and environmental sustainability in public contexts: Application to hand-drying options. WIT Transactions on Ecology and the Environment, vol. 222, WIT Press: Southampton and Boston, pp. 59-71, 2019.

[15] Venuto, A., Schiavon, M., Rada, E.C. \& Ragazzi, M., Sustainable mobility strategies in an Italian university. UPB Scientific Bulletin, Series D: Mechanical Engineering, 81, pp. 289-300, 2019.

[16] Piano Sostenibilità Ambientale 2016/2018 (in Italian), University of Trento. www.unitn.it/alfresco/download/workspace/SpacesStore/d908fl bb-eb75-4ff9-bdf65ad72c27f2bf/0095_20_pianoSostenibilita_web.pdf. Accessed on: 20 Oct. 2020.

[17] Google Earth. earth.google.com/web/. Accessed on: 21 Jan. 2021.

[18] Rada, E.C., Magaril, E.R., Schiavon, M., Karaeva, A., Chashchin, M. \& Torretta, V., MSW management in universities: Sharing best practices. Sustainability, 12, p. 5084, 2020.

[19] Ural Federal University, About the university UrFU. urfu.ru/en/about-the-university/. Accessed on: 30 Oct. 2020.

[20] Ural Federal University, UrFU development strategy (in Russian). strategy.urfu.ru/fileadmin/user_upload/common_files/news/2019/Programma_razviti ja.pdf. Accessed on: 2 Nov. 2020.

[21] National Aeronautics and Space Administration (NASA), In-flight carbon dioxide exposures and related symptoms: Associations, susceptibility and operational implications, TpP-2010-216126, 2010.

[22] Ragazzi, M., Albatici, R., Schiavon, M., Ferronato, N. \& Torretta, V., $\mathrm{CO}_{2}$ measurements for an unconventional management of indoor air quality. WIT Transactions on Ecology and the Environment, vol. 230, WIT Press: Southampton and Boston, pp. 59-71, 2019.

[23] United Nations (UN), Department of Economic and Social Affairs - Sustainable Development. https://sdgs.un.org/goals. Accessed on: 20 Oct. 2020.

[24] Network of Universities for Sustainable Development (RUS), Cambiamenti climatici (in Italian). sites.google.com/unive.it/rus/gruppi-di-lavoro/cambiamenti-climatici. Accessed on: 21 Oct. 2020.

[25] Ragazzi, M. \& Ghidini, F., Environmental sustainability of universities: Critical analysis of a green ranking. Energy Procedia, 119, pp. 111-120, 2017.

[26] Torretta, V., Tolkou, A., Katsoyiannis, I. \& Schiavon, M., Second-hand smoke exposure effects on human health: Evaluation of $\mathrm{PM}_{10}$ concentrations in the external areas of a university campus. Sustainability, 12, p. 2948, 2020.

[27] Karpov, I. \& Anufriev, V. The influence of "Green" economy on "Green" universities formation in the concept of metamodern world (in Russian). elar.urfu.ru/handle/10995/80143. Accessed on: 30 Oct. 2020.

[28] Kaminov, A., Anufriev, V., Nikitin, M. \& Oborin, O., On the need for universities to participate in the UI green metric world sustainable development rating (on the example of UrFU). Economics: Yesterday (in Russian). Today and Tomorrow, 9(3A), pp. 466-475, 2019. 